\title{
Rancang Bangun Smart Glass Telemetri Tegangan Menggunakan Teknik Simplex Berbasis Arduino Nano
}

\author{
"Saniman, Mukhlis Ramadhan, Iskandar Zulkarnain \\ Program Studi Sistem Komputer, STMIK Triguna Dharma \\ Jl. A.H Nasution No.73 Medan, Indonesia, 20142 \\ E-mail: sanisani.murdi@gmail.com
}

\begin{abstract}
Abstrak
Perkembangan terbaru dalam teknologi telah menyebabkan munculnya perangkat terbaru yang baru muncul seperti kacamata pintar. Biasanya, perangkat elektronik konsumen dirancang untuk manfaat dan fungsi-fungsi yang dapat mereka berikan, dan aspek keamanan itu diunduh belakangan di intinya, sebuah kaca yang cerdas didasarkan pada komponen-komponen yang ada didalam ponsel pintar modern. Dengan demikian, akan berbagi ancaman keamanan serupa. Mengindentifikasi ancaman keamanan dan masalah privasi dipihak saya yang cerdas dari dua sudut pandang yang sama, dan juga mengusulkan solusi awal untuk mengatasi risikorisiko tersebut. Ini termasuk, saran dua faktor penentu untuk kacamata cerdas berdasarkan pin atau suara yang di kombinasikan dengan scan iris. Tujuan dari pekerjaan ini untuk memeriksa pemerintah saat ini adalah seni kacamata cerdas yang aku terapkan, dan analisis yang ada dan potensi keamanan dan masalah privasi dan privasi. Teknologi ini menawarkan banyak potensi untuk perusahaan dan masyarakat, yang dibahas dalam artikel ini. Demikian keterangan yang digunakan manager dan peneliti tetntang teknologi dan diskusi.
\end{abstract}

Kata kunci : Smart Glass, Kaca Lensa, Push Button, Oled Display

\begin{abstract}
The latest developments in technology have led to the emergence of new emerging devices such as smart glasses. Typically, consumer electronic devices are designed for the benefits and functions they can provide, and the security aspect is downloaded later in essence, an intelligent glass based on the components present in modern smart phones. As such, it will share similar security threats. Identifying security threats and privacy issues on my smart side from two points of view, and also proposing initial solutions to address those risks. This includes, suggesting two determinants for smart glasses based on pins or sound in combination with iris scans. The purpose of this work to examine the current government is the art of smart glasses that I apply, and the existing analysis and potential security and privacy and privacy issues. This technology offers a lot of potential for companies and society, which is discussed in this article. Such information is used by managers and researchers about technology and discussion.
\end{abstract}

Keywords: Smart Glass, Lens Glass, Push Button, Oled Display 


\section{PENDAHULUAN}

Perkembangan teknologi digital menghasilkan banyak ciptaan baru yang member kemudahan bagi manusia dalam pekerjaannya. Teknologi digital yang menjadi dasar pembuatan sebuah computer telah berkembang pesat sehingga banyak komponen atau sensor yang diciptakan dengan ukuran yang cukup kecil. Salah satu komponen yang baru dikembangkan misalnya teknologi display oled. Display oled merupakan pengembangan dari teknologi led dengan resolusi yang lebih tinggi.

Kini telah tersedia display oled ukuran kecil atau miniatur. Display dengan ukuran yang mini dan kompak ini dapat dikembangkan menjadi sebuah lensa pintar atau smart glass. Pengertian smart glass adalah sebuah glass atau kacamata yang dapat mengirim atau menampilkan informasi pada pemakainya secara langsung pada kacamata itu sendiri. Pemakai kacamata atau smart glass dapat membaca informasi misalnya suatu nilai data melalui lensa kacamata secara langsung sambil bekerja.

\section{METODE PENELITIAN}

\subsection{Arduino}

"Arduino ialah suatu perangkat / kit elektronik yang bersifat open source yang memiliki komponen utama berupa sebuah mikro jenis AVR dari perusahaan Atmel,yang berupa chip atau Integrated Circuit (IC) yang dapat diprogram dengan menggunakan komputer." fitri, dkk (2014:2)

\subsection{Kaca Lensa}

Lensa merupakan salah satu alat yang dapat membantu kegiatan manusia, seperti lensa yang terdapat pada mikroskop yang berfungsi sebagai memperbesar bayangan yang ditangkap oleh mikroskop, sehingga benda yang sangat kecil yang tak mampu dilihat dengan mata telanjang dapat terlihat dengan jelas dengan menggunakan mikroskop.

Selain itu ada juga lensa yang terdapat pada kaca mata, bagi penderita rabun dekat atau jauh, memerlukan sebuah kaca mata yang terdiri dari lensa cembung atau cekung fungsi lensa pada kaca mata ini adalah membantu penglihatan bagi para penderita rabun jauh maupun rabun dekat, sehingga benda yang tidak terlihat jelas bagi penderita yang mengalami rabun jauh atau dekat dapat melihat benda

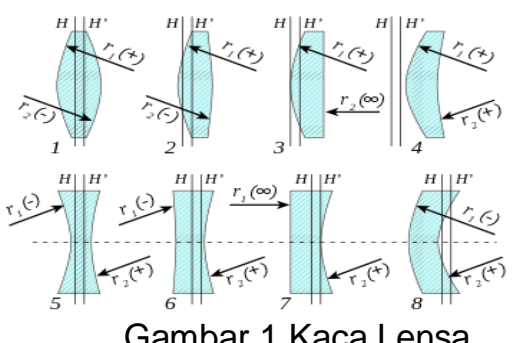

\subsection{Push Button ( Tombol)}

Tombol tekan (push button) adalah bentuk saklar yang paling umum dari pengendali manual yang dijumpai di industri. tombol tekan NO (Normaly Open) menyambung rangkaian ketika tombol ditekan dan kembali pada posisi terputus ketika tombol dilepas. Tombol tekan NC (Normally Closed) akan memutus rangkaian apa bila tombol ditekan dan kembali pada posisi terhubung ketika tombol dilepaskan.ada juga tombol tekan yang memiliki fungsi ganda, yakni 
sudah dilengkapi oleh dua jenis kontak, baik itu NO maupun NC. jadi tombol tekan tersebut dapat difungsikan sebagai NO, NC maupun keduanya. ketika

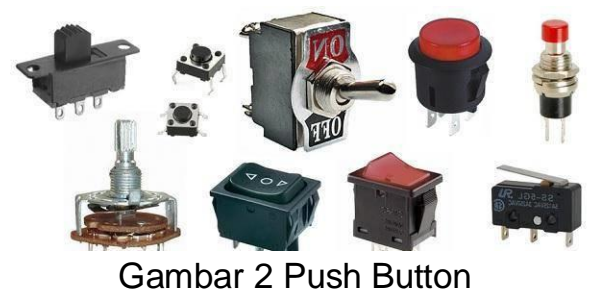

\subsection{Akrilik}

(Acrylic) adalah plastik yang menyerupai kaca, tetapi mempunyai sifat-sifat yang membuatnya lebih unggul dari pada kaca dalam banyak sistem salahsatunya dari perbedaan sifatnya merupakan dari kelenturan dari akrilik (Acrylic) itu sendiri. Tapi dulu merek kelas tinggi akrilik (Acrylic) dinamakan polycast, Lucite dan Plexiglas.akrilik (Acrylic) tak gampang pecah, bahan ringan dan juga gampang untuk dipotong, dikikir, dibor, dihaluskan, dikilapkan dan dicat. perabotan, patung, produk display, hiasan dan lain sebagainya

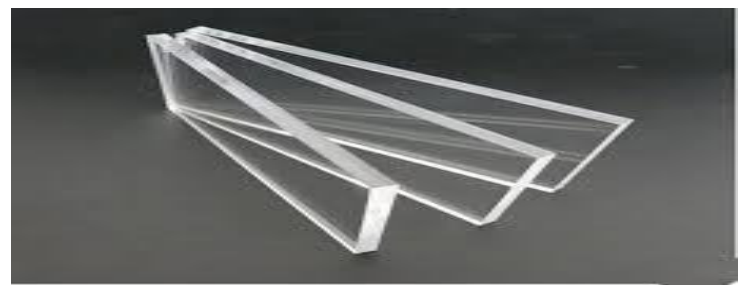

\subsection{Modul Bluetooth HC-05}

Gambar 3 Akrilik

Bluetooth adalah protokol komunikasi wireless yang bekerja pada frekuensi radio 2.4 $\mathrm{GHz}$ untuk pertukaran data pada perangkat bergerak seperti PDA, laptop, HP, dan lain-lain1 . Salah satu hasil contoh modul Bluetooth yang paling banyak digunakan adalah tipe HC-05. modul Bluetooth HC-05 merupakan salah satu modul Bluetooth yang dapat ditemukan dipasaran dengan harga yang relatif murah. Modul Bluetooth $\mathrm{HC}-05$ terdiri dari 6 pin konektor, yang setiap pin konektor memiliki fungsi yang berbeda - beda

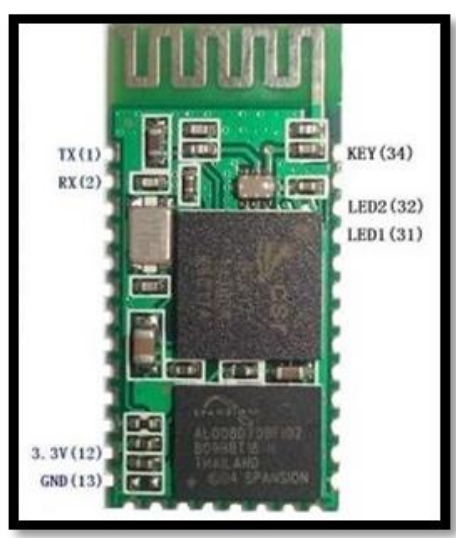

Gambar 4 Modul Bluetooth HC-05

\subsection{Oled}

J-SISKO TECH Vol. 3, No. 1 Januari , 2019: 12-18 
Oled display disebut juga organic Led adalah display grafik dengan ukuran 0.96 inci dan resolusi 128x64 pixe/ menggunakan teknologi Oleddisplay Oled biasanya terbuat dari karbon dan hidrogen.Untuk komunikasi dengan Mikrokontroler Arduino menggunakan Komunikasi I2C, menggunakan 2 pin yaitu pin sda dan pin scl sehingga menghemat pin.

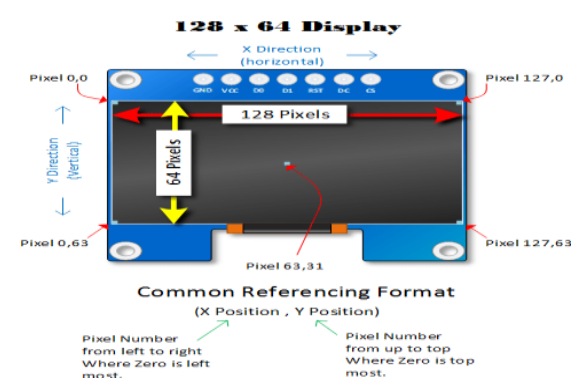

Gambar 5 Oled Display

\subsection{Resistor}

Resistor adalah komponen elektronika yang berfungsi untuk menghambat atau membatasi aliran listrik yang mengalir dalam suatu rangkain elektronika. Sebagaimana fungsi resistor yang sesuai namanya bersifat resistif dan termasuk salah satu komponen elektronika dalam kategori komponen pasif.

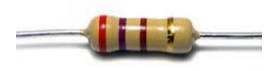

Gambar 6 Resistor

\subsection{Sensor Tegangan}

Sensor tegangan berfungsi membaca nilai tegangan suatu rangkaian. Arduino dapat membaca nilai tegangan dengan memanfaatkan pin analog. Jika range tegangan yang dibaca diantara 0-5 V bisa langsung menggunakan pin analog, sedangkan jika range tegangan yang dibaca $>5 \mathrm{~V}$ harus menggunakan rangkaian tambahan yakni pembagi tegangan karena pin arduino bekerja pada max $5 \mathrm{v}$

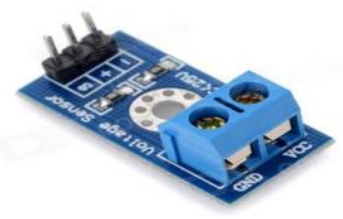

Gambar 7 Sensor Tegangan

\section{ANALISA DAN HASIL}

\subsection{Algoritma Sistem}

Algoritma adalah langkah-langkah atau tahapan proses yang dilakukan oleh sistem dalam mengolah input menjadi output selama 1 sikluskerja. Rancangan alat pemantau 
tegangan pada proses pengukuran tegangan memiliki beberapa tahap proses. berikut ini akan diuraikan tahapan proses mulai dari input hingga output.

Berikut merupakan tahapan proses sistem sebagai berikut :

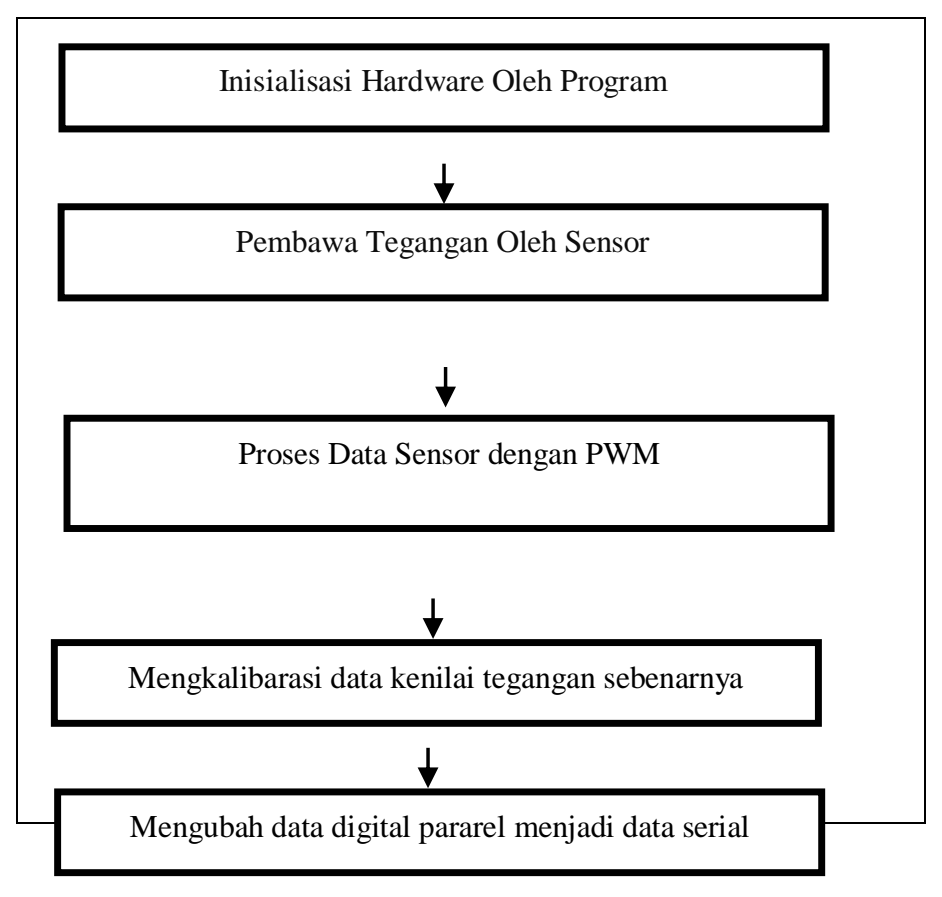

\subsection{Penerapan Teknik Simplex}

Simplex adalah salah satu bentuk komunikasi antara dua belah pihak, hanya saja sinyal-sinyal yang dikirim secara satu arah. biasanya metode simplex ini dimanfaatkan oleh teknologi seperti televisi dan radio. Konsep ini bisa diterapkan pada metode broadcasting penyiaran televisi dan radio.

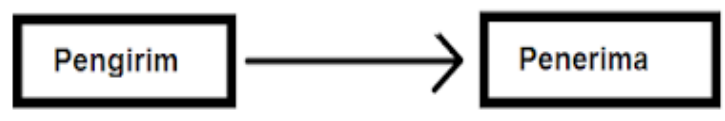

Simplex

Gambar 10 Teknik Simplex

\subsection{Diagram Blok}

Konfigurasi sistem diperlihatkan pandangan berblok diagram diatas. gambar menunjukkan bagian-bagian system seperti input, proses ,transmisi data dan display atau output. Input terdiri dari sensor yaitu sensor tegangan. Sensor tegangan dibuat dengan beberapa komponen seperti trafo step down, penyearah dan pembagi tegangan 


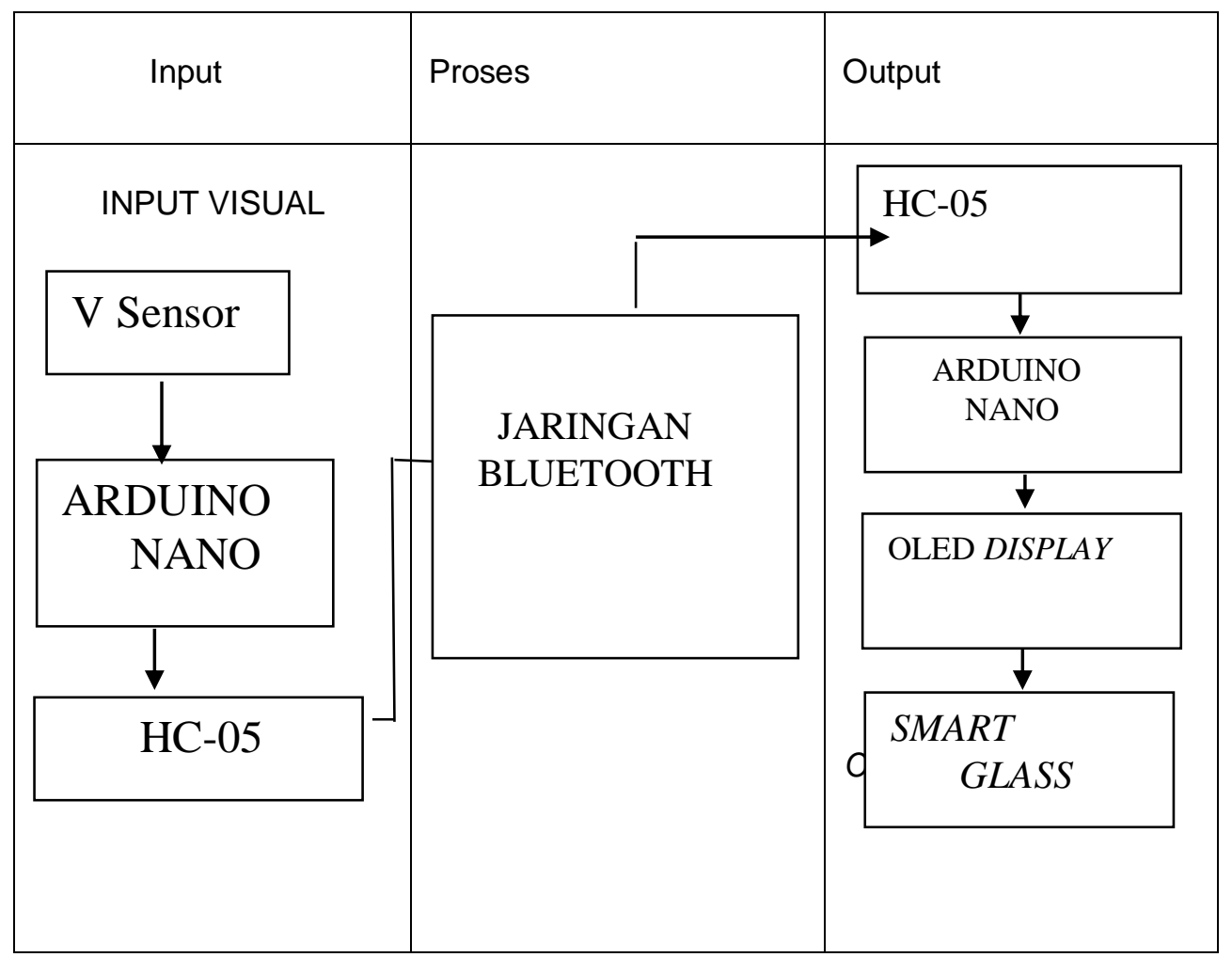

Gambar 11 Blog Diagram

\subsection{Implementasi Sistem}

Implementasi sistem merupakan proses untuk merealisasikan sistem yaitu membangunsebuah sistem agar yang bekerja sesuai tujuan yang dibuat, pada umumnya dimulai dengan rancangan blok diagram, perakitan komponen, pembuatan program, hingga membuat kesimpulan dari hasil pengujian. Setelah semua komponen sistem telah tersedia ,maka langkah selanjutnya adalah merancang dan membangun sistem sesuai perencanaan.

\subsection{Rangkaian Kontroller Arduin Nano}

Terdapat 2 unit arduino nano yang digunakan yaitu Rangkaian yang berfungsi mengukur tegangan, dalam hal ini adalah proses pembacaan tegangan dari objek yang diukur dan rangkaian yang menampilkan data pada display oled. Kedua modul rangkaian terhubung secara nirkabel menggunakan sepasang bluetooth adapter.

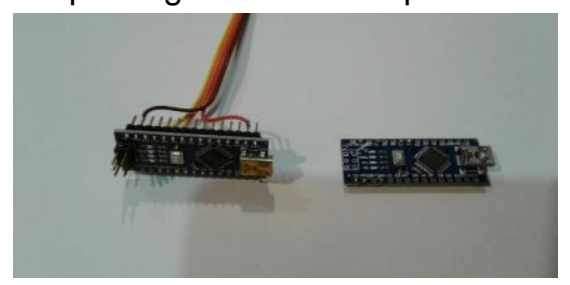


Gambar 12 Rangkaian Arduino pengirim Data

\section{KESIMPULAN}

Berdasrkan penelitian yang telah dilakukan, dapat diambil kesimpulan dari sebagai berikut :

1. Dari pengujian yang telah dilakukan dapat diambil kesimpulan bahwa alat pemantau tegangan berbasis arduino nano berhasil dibuat atau direalisasikan.

2. Pemancar bluetooth $\mathrm{HCO} 5$ akan mengirim data hasil pembacaan tegangan pada bluetooth penerima dan ditampilkan pada display oleh oleh arduino nano.

3. Arduino nano pada bagian pembaca tegangan akan melakukan kalibrasi terlebih dahulu untuk memperoleh nilai tegangan sebenarnya sebelum mengirimnya ke rangkaian display.

4. Jarak pancar terima maksimal dari perangkat bluetooth setelah diuji coba adalah 25 meter dengan kondisi tanpa halangan.

\section{REFERENSI}

[1] Andrianto,H.,\&Darmawan, A.,2017.Arduino Belajar Cepat Dan Pemogramman, Bandung : Informasi Dan informatika.

[2] Rafiudin,R., 2018, Sistem Komunikasi Data Mutakhir.Yogyakarta: Andi

[3] Team Work STMIK TRIGUNA DHARMA MEDAN 2018 Workshop TA/SKRIPSI,Medan.

[4] Wahana.K.,(2014).Google Sketch Up.Yogyakarta: Andi

[5] Wahana Komputer ., 2015.,Buku Pintar Memilih Ponsel dan Tablet Berbasis Android.Yogyakarta :Andi.

[6] Wikipedia. Com;https://Wikipedia.com-pengertian Smart glass 